\title{
DOS PROBLEMAS CONCERNIENTES A LA EXCEPTIO REI IUDICATAE VEL IN IUDICIUM DEDUCTAE EN LOS TRABAJOS DE LOS JURISTAS ROMANOS CLÁSICOS*
}

\author{
TWO PROBLEMS CONCERNING THE LA EXCEPTIO REI IUDICATAE \\ VEL IN IUDICIUM DEDUCTAE IN THE WORKS OF THE CLASSICAL \\ ROMAN JURISTS
}

\section{HANs ANKum ${ }^{* *}$}

En todos los sistemas actuales de derecho privado existen normas que impiden la posibilidad de un segundo juicio sobre el mismo asunto y entre las mismas partes. En estos sistemas se trata de un efecto de la sentencia del juez. La cuestión de la autoridad de la cosa juzgada es temida no solo por los estudiantes, sino también por los profesores. En derecho romano, este tema es aún más complicado, ya que, en primer lugar, a la preclusión de la sentencia del juez se agrega la que es provocada por la litis contestatio, y en segundo lugar, había grandes diferencias entre los tres sistemas de procedimiento civil conocidos por los romanos, a saber el de las acciones de la ley, el del procedimiento formulario y el de la cognitio extra ordinem.

En este trabajo me ocuparé solamente del procedimiento formulario. En el marco de este procedimiento, y respecto a la

\footnotetext{
Este trabajo forma parte del Proyecto Anillo de Investigación Asociativa, en Ciencias Sociales, "Estudios Histórico-Dogmáticos de Derecho Patrimonial Privado: una mirada a los artículos de los Libros II y IV del Código Civil de Chile", SOC 1111, de CONICYT. El autor agradece la traducción de este trabajo al español realizada por el Profesor Doctor Gabriel Bocksang Hola de la Pontificia Universidad Católica de Chile.

* Catedrático Emérito de la Universidad de Amsterdam, Holanda.
}

preclusión, había una diferencia importante entre la mayoría de los juicios y la minoría de los juicios. En la mayoría de los procesos era imposible un segundo litigio sobre la misma materia y entre las mismas partes, en razón de la oposición, por parte del demandado, de la exceptio rei iudicatae vel in iudicium deductae. En una minoría de los procesos, la preclusión se efectuaba a través de la extinción ipso iure de la acción instituida para la segunda vez, provocada por la primera litis contestatio.

Para poder explicar cuándo se trataba de los casos concernientes a la mayoría de los procesos y cuándo de aquellos concernientes a la minoría de los procesos, debemos hacer una clara distinción entre los iudicia legitima y los iudicia imperio continentia. Iudicia legitima eran procesos que se llevaban a cabo en Roma, entre partes que eran cives Romani y frente a un unus iudex. Todos los procesos en los que faltaba alguno de estos tres elementos eran iudicia imperio continentia, procesos fundados sobre el poder del magistrado, es decir, el pretor. Respecto a una categoría de los iudicia legitima la preclusión de la acción era efectuada a través de una extinción ipso iure consecuencial a la litis contestatio. Esta categoría restringida era la de las acciones in personam que tenían una fórmula con una 
intentio in ius. Según la opinión general de los romanistas, la preclusión era provocada en estos procesos por la litis contestatio y se fundaba siempre en la deductio in iudicium independientemente de la sententia indicis. Pugliese ${ }^{1}$ la ha formulado, con su claridad habitual, de la siguiente manera: "la consummazione ipso iure... significava la definitiva estinzione del rapporto sostanziale e non veniva modificata dalla successiva pronunzia della sentenza”. Para todos los otros procesos, la preclusión operaba por la oposición de la exceptio rei iudicatae vel in iudicium deductae, es decir, la excepción basada en el hecho de que el asunto ha sido objeto de la sentencia de un juez o de una litis contestatio, de un acuerdo de las partes sobre el contenido del litigio controlado por el pretor al final de la fase in iure. Esta excepción era aplicable a todos los iudicio imperio continentia y a los iudicia legitima cuando se interponía una acción real o una actio in personam que tuviera una formula con una intentio in factum. En todos estos casos, el demandado que opone la exceptio rei indicatae vel in indicium deductae se funda sobre el hecho de que el asunto ya ha sido objeto de la sentencia de un juez o de una deducción en justicia. Esta conferencia versará exclusivamente sobre la exceptio rei iudicatae vel in iudicium deductae en el marco del proceso per formulam durante el período clásico.

Dos problemas concernientes a esta excepción serán examinados a continuación. En la primera parte, trataremos la cuestión de la dualidad o unidad de la excepción. La segunda parte, tiene por tema la relación entre la litis contestatio y la sentencia del iudex en nuestra excepción.

\footnotetext{
1 Pugliese (1985): Scritti giuridici scelti, II (Napoli) pp. 146-147.
}

Aquí, las palabras claves son superposición o absorción.

\section{LA UNIDAD DE LA EXCEPTIO REI IUDICATAE VEL IN IUDICIUM DEDUCTAE}

La reconstitución generalmente aceptada de dos cláusulas que forman conjuntamente la exceptio rei indicatae vel in iudicium deductae (en adelante exceptio r. $i$. vel in i. d.) es la siguiente: "si ea res qua de agitur iudicata non est inve iudicium deducta non est" ("si este asunto que es el objeto del proceso no ha sido juzgado por una sentencia del juez o no ha sido deducido en justicia”).

Un problema frecuentemente discutido por los romanistas del siglo veinte respecto a esta excepción es el de su unidad o su dualidad. Se ha expresado tres opiniones sobre este punto.

Según la primera se trata de una excepción única. Una sola excepción ha sido interpuesta bajo la rúbrica rei iudicatae vel in iudicium deductae en la parte del edicto consagrada a las excepciones. Ésta era verdaderamente una sola excepción stricto sensu; el pretor la ha propuesto en su edicto como una unidad, y las partes de un proceso concreto incorporaban y debían incorporar en la formula, siempre y en su totalidad, las palabras si ea res qua de agitur iudicata non est inve iudicium deducta non est. Según esta opinión se trata de una excepción compuesta de dos cláusulas: una sobre la res iudicata y otra sobre la res in iudicium deducta. Por consiguiente, el pretor no permitió jamás al demandado que opusiera como excepción una sola de las dos alternativas comprendidas en la excepción.

La segunda teoría es la siguiente. Bajo la rúbrica rei indicatae vel in iudicium 
deductae del edicto, era propuesta una excepción cuya redacción era si ea res qua de agitur iudicata non est inve iudicium deducta non est. Sin embargo, en cada proceso concreto las partes incorporaban (con la autorización del pretor) solo una de las dos alternativas de la excepción propuesta en el edicto. Es decir que la formula de un proceso concreto contenía, o bien las palabras si ea res qua de agitur iudicata non est, o bien las palabras si ea res qua de agitur in iudicium deducta non est.

La tercera opinión sostenida por algunos romanistas consiste en que el edicto del pretor contenía dos excepciones separadas: una exceptio rei iudicatae y una exceptio rei in iudicium deductae. En un proceso concreto una de estas dos excepciones era incorporada en la formula.

La gran mayoría de los romanistas adhiere a la segunda o a la tercera teoría. Lenel sostuvo en un principio, en la primera edición de su Das Edictum Perpetuum de 1883, la primera teoría; luego cambió de opinión y devino defensor de la segunda teoría. En un estudio titulado "Deux problèmes relatifs à l'exceptio rei iudicatae vel in iudicium deductae dans la procédure formulaire du droit romain classique" ${ }^{2}$, yo expresaba la opinión de que la primera teoría era exacta, siendo yo entonces el único romanista del siglo veinte en defender esta posición. A ella se sumaron Karl Hackl ${ }^{3}$ y Matteo Marrone en un artículo "Res in iudicium deducta"-"Res iudicata", publicado

\footnotetext{
2 Ankum, Hans (1984): "Deux problèmes relatifs à l'exceptio rei iudicatae vel in iudicium deductae dans la procédure formulaire du droit romain classique", Études Petropoulos $=(2007)$ : Extravagantes $($ Napoli $)$ pp. 73-97.

3 Kaser, Max-Hackl, Karl (1996): Das Römische Zivilprozessrecht (München, C.H. Beck'sche Verlagsbuchhandlung), p. 302.
}

en el BIDR del mismo año ${ }^{4}$. Cito a Marrone: "Non può... essere revocata in dubio l'unicità dell'exceptio rei indicatae vel in iudicium deductae" ${ }^{5}$, quien añade enseguida "si deve ritenere... che nella formula si usasse inserire ogni volta il testo dell'eccezione tutto intero, con le due clausole" 6 .

Quien se empeñe en la reconstitución del derecho romano clásico no puede estar siempre seguro de los resultados de sus investigaciones, pero en este caso estoy completamente seguro de la unidad en los dos sentidos indicados en el seno del derecho romano clásico. Esta teoría, sin embargo, no ha sido aceptada de manera general y es por ello que quiero expresar aquí algunos argumentos en su favor. Se trata de argumentos fundados en el funcionamiento del proceso formulario y de argumentos textuales.

Los argumentos que conciernen a la manera en que el proceso per formulam funcionó son bastante complicados. Los he formulado en mi artículo de 1984 e intentaré de formularlos ahora de mejor manera. Quiero mostrar cuáles habrían sido las consecuencias prácticas no deseadas de un régimen según el cual una de las dos alternativas de la excepción podía ser opuesta. Ellas habrían sido tan injustas que nos fuerzan a reconocer que el pretor no admitió jamás que una sola de las dos alternativas de la exceptio r. $i$. vel in $i$. $d$. fuera opuesta.

Analizaremos en primer lugar el caso en el que, luego de un primer proceso que ha concluido por una sentencia del juez, una segunda litis contestatio ha tenido lugar entre las mismas partes sobre el mismo asunto y la

\footnotetext{
4 Marrone, Matteo (1996): "Res in iudicium deducta"-"Res iudicata", Bullettino dell' Istituto di Diritto Romano "Vittorio Scialoja", No 38, pp. 63-81= (2003): Scritti Giuridici, II (Palermo) pp. 585-628.

5 Marrone (1996) $=(2003)$ pp. 592-593.

6 Marrone $(1996)=(2003)$ p. 593.
} 
exceptio rei iudicatae ha sido opuesta. Luego, mientras el primer proceso se lleva a cabo ante un juez, se prueba por una de las partes que la sentencia del primer proceso es nula, mientras la primera litis contestatio es perfectamente válida. Tal nulidad puede fundarse sobre el hecho que la sentencia ha sido pronunciada después de la mors litis, o que ella ha excedido la instrucción del juez contenida en la formula. Es posible también que el pretor haya anulado la sentencia del primer proceso por una restitutio in integrum (por ejemplo, en caso de metus). En este caso, el demandado que quiere invocar la deductio in iudicium del primer proceso no puede hacerlo, puesto que la formula no contiene la cláusula que se refiere a esta deductio. Así las cosas, el juez del segundo proceso pronunciará una sentencia, lo que es contrario al principio ne bis in idem.

El siguiente es otro caso para probar que una excepción que contuviera solamente una de las dos alternativas de la exceptio $r$. $i$. vel in $i$. $d$. no podía ser opuesta en un segundo proceso sobre la misma cuestión. En el primer proceso una sentencia no ha sido aún pronunciada en el momento de la litis contestatio del segundo proceso, o ella ha sido ya pronunciada sin que las partes estuvieran al tanto en dicho momento, ya que ellas eran representadas por cognitores. Si el defensor opuso la exceptio rei in iudicium deductae, y si durante la fase apud iudicem del segundo proceso llega a su conocimiento la sentencia del juez del primer proceso, él no se halla habilitado para invocar la res iudicata, pues esta alternativa no está incluida en la formula. Él no tiene tampoco el derecho de invocar la deductio in iudicium, porque este derecho ha sido absorbido por la sentencia del primer proceso, como lo veremos en la segunda parte de esta conferencia. El resultado injusto es que el deman- dado debe aceptar una segunda sentencia y puede ser condenado por segunda vez.

Una reflexión sobre el funcionamiento del proceso formulario conduce, por lo tanto, a la conclusión de que la oposición de una de las dos alternativas de la excepción estudiada por nosotros no ha sido permitida y que en cada caso de un segundo proceso entre las mismas partes de eadem re el demandado podía solamente y debía oponer la exceptio r. $i$. vel in $i . d$. con su redacción completa.

También hay argumentos textuales que llevan al mismo resultado. En los tres textos en los que Gayo habla de nuestra excepción en sus Institutas (a saber, Inst. $3.181 ; 4.106 ;$ y 4.107), él la menciona siempre con el texto completo y la trata como una única institución procesal. Otros argumentos pueden ser hallados en fragmentos de juristas clásicos que los compiladores han incorporado en el título 44.2 del Digesto, titulado De exceptione rei iudicatae. En algunos fragmentos de mayor extensión se constata que en un parágrafo se aborda la cláusula relativa a la res in iudicium deducta de nuestra excepción y en otro parágrafo se aborda la cláusula sobre la res iudicata; cf., por ejemplo, Ulpiano D. 44.2 .11 pr. y D. 44.2.11.5: en el primer parágrafo el jurista se refiere a un llamado a la res iudicata, y en el parágrafo 5, a un llamado a la res in iudicium deducta. En fin, hay en el título 44.2 del Digesto varios textos que conciernen a nuestra excepción, en los cuales no se ha precisado si el primer proceso ha concluido o no por una sentencia. Al parecer no era esencial para el jurista de informarlo al lector, porque la excepción tratada contenía las dos alternativas y los demandados habían podido invocar en estos casos a una u otra de las cláusulas de la excepción. Doy a modo de ejemplo los parágrafos 2 y 3 del 
fragmento D. 44.2.21 de Pomponio. Según el parágrafo 2 de este fragmento, el demandado puede invocar la cláusula de re iudica$t a$, mientras que en el parágrafo siguiente, se examina la posibilidad de invocar la cláusula sobre la deductio in iudicium.

La conclusión de esta primera parte puede ser breve. Es absolutamente cierto que las dos cláusulas de la exceptio r. $i$. vel in $i$. d. se hallaban, ambas, en el modelo de la excepción expuesto en el edicto del pretor, y que era la excepción entera la que debía ser insertada en la formula de cada proceso.

\section{LA RELACIÓN ENTRE LA LITIS CONTESTATIO Y LA SENTENCIA DEL JUEZ EN LA EXCEPTIO REI IUDICATAE VEL IN IUDICIUM DEDUCTAE. ¿SUPERPOSICIÓN O ABSORCIÓN?}

El segundo problema, que nos ocupará por más tiempo que el primero, es el de la relación de las dos cláusulas de nuestra excepción: la que versa sobre la res iudicata y la que versa sobre la res in iudicium deduc$t a$, es decir, la que versa sobre la sentencia del juez y la que versa sobre la litis contestatio en el proceso anterior. La gran mayoría de los romanistas del siglo veinte sostenía que se trataba de una superposición o cúmulo. Según estos autores, la invocación de la litis contestatio era el elemento esencial de la excepción, pues el demandado en el nuevo proceso debía - según ellos - fundarse sobre la deductio in iudicium tanto cuando ésta había sido seguida de una sentencia, como cuando una sentencia válida no había sido pronunciada del todo, o no había sido pronunciada por el momento. Ante una identidad de la res in iudicium deducta y de la res iudicata, el hecho de que había habido deducción en justicia era decisivo para estos autores. El hecho de que una sentencia había sido rendida sobre el asunto no entraba en juego, según ellos, porque la acción ya había sido consumida por la deducción en justicia.

En 1984, en el artículo publicado en los Études Petropoulos ${ }^{7}$, ya mencionado, defendí la teoría de la absorción respecto de la preclusión iure exceptionis. En esta teoría, la cláusula sobre la deductio in iudicium no juega un rol jurídico sino en los casos de litispendencia y de mors litis. Pocos autores me habían precedido; menciono aquí los nombres de Liebs y de Pugliese. La opinión que expresé en 1984 fue aceptada en 1996 por Karl Hackl, refiriéndose a la exceptio r. i. vel in i. d., dicho autor escribe: "Auf Grund dieser exceptio ... hat der Richter freizusprechen, wenn de eadem re bereits in einer anderen actio durch Urteil entschieden worden ist. Bei dieser exceptio stellt man jetzt grundsätzlich auf die res iudicata ab" ". El mismo año 1996, Matteo Marrone9 criticó, en su artículo publicado en BIDR, ya mencionado, la teoría que yo sostuve. Traté el problema de la relación entre las dos cláusulas de la exceptio r. i. vel in i. $d$. ampliamente en un estudio publicado en los Studi Metro $^{10}$, donde intenté refutar la crítica de Marrone. La mayor parte de los autores son, empero, defensores de la teoría del cúmulo.

Ciertamente vale la pena volver sobre el problema de la relación entre las dos cláusulas de la exceptio r. i. vel in i. d. y defender una vez más el régimen de la ab-

\footnotetext{
Ankum (1984) = (2007) pp. 73-97.

8 Kaser-Hackl (1996) p. 302.

9 Marrone (1996) = (2003) pp. 585-605.

10 Ankum, Hans (2009): Studi Metro, vol. I (Milano) pp. 25-50.
} 
sorción. Para probar que los juristas clásicos aplicaron este sistema y que no siguieron el régimen de la superposición o cúmulo, queremos estudiar el título (el nombre) de nuestra excepción y cinco textos de Gayo y de Ulpiano. Estos textos nos muestran cuál era, según estos juristas, la relación entre la cláusula sobre la res iudicata y aquélla sobre la deductio in iudicium.

En primer lugar, examinemos de más cerca el título de la exceptio r. $i$. vel in i. d. Si la teoría de la superposición fuera exacta, este título habría sido diferente en dos puntos. En primer lugar, de haberse tratado de un caso de cúmulo de los dos fenómenos, los que hubieran contribuido conjuntamente a la preclusión de la acción, la palabra et hubiera debido figurar en el título de la excepción en lugar del vocablo vel. Y en segundo lugar, el título de la excepción hubiera debido comenzar por la cláusula sobre la deductio in iudicium. Ello por dos razones. La primera concierne la importancia de la litis contestatio, la que en la teoría del cúmulo es mayor que la de la res iudicata, ya que la cláusula sobre la res in iudicium deducta de la excepción es también aplicable cuando una sentencia ha sido pronunciada en el proceso anterior. La segunda razón es que no se podría comprender por qué en la indicación de la excepción no se respetó el orden cronológico. El título que deberíamos haber encontrado, de ser exacta la teoría del cúmulo, no es el que encontramos en las fuentes: exceptio rei iudicatae vel in iudicium deductae. Ahora bien, ello se explica fácilmente si se sigue la teoría de la absorción: la deductio in iudicium pierde su importancia en la mayor parte de los casos en los que su efecto ha sido absorbido por el pronunciamiento de la sentencia. El efecto preclusivo de la deductio in iudicium ha sido absorbido por el de la res iudicata.
Llegamos ahora a la interpretación de cinco textos de Gayo y de Ulpiano que nos muestran cuál era, según los juristas clásicos, la relación entre las dos cláusulas de la exceptio r. $i$. vel in i. d. Los textos de Ulpiano nos enseñan también las opiniones de Neracio y de Juliano. Veremos que en el segundo proceso, no se pone ninguna atención a la deductio in iudicium, sino que solamente a la sentencia del primer proceso. Los adherentes a la teoría del cúmulo dirán sin duda que los compiladores eliminaron las observaciones de los juristas clásicos sobre la segunda cláusula; y, según ellos, las observaciones que encontramos en los textos del Digesto referentes a la res iudicata en el proceso anterior, fueron agregadas por los compiladores. La tesis de esta doble intervención de los miembros de la comisión de Triboniano no me ha convencido. No acepto ni las interpolaciones por las cuales la argumentación del jurista fundada sobre la deductio in iudicium habría sido eliminada, ni aquéllas por las cuales la argumentación fundada sobre la res iudicata habría sido añadida.

No se encuentra nada en los textos de los juristas sobre la litis contestatio, ya que sus efectos habían sido absorbidos en el derecho clásico por los de la sentencia del juez. Y, como lo veremos en un instante, los textos de Ulpiano D. 44.2.9.1, D. 44.2.9.2 y D. 44.2.11.3 contienen indicaciones muy fuertes para la clasicidad de las argumentaciones fundadas sobre la res iudicata. Todo aquello me conduce a la opinión según la cual los compiladores no han hecho nada más que eliminar la segunda parte del título de nuestra excepción y la preclusión de la litis contestatio, la que en derecho clásico operaba solamente en los casos de litispendencia o de mors litis, es decir, cuando la deducción en justicia no había sido (aún) seguida por una sentencia judicial. 
Efectuaremos a continuación una exégesis de un texto de Gayo y de cuatro textos de Ulpiano que serán presentados en orden didáctico. El primer texto, Gayo D. 44.2.17 es relativamente simple; el último texto, Ulpiano D. 44.2.11.3 es bastante complicado. El encanto de la interpretación de estos textos es que nos lleva a conocer casos prácticos en los que los juristas han debido encontrar soluciones razonables que conciernen la preclusión de una acción según el derecho pretorio.

\section{44.2.17 Gaius l.30 ad edictum pro- vinciale}

Si rem meam a te petiero, tu autem ideo fueris absolutus, quod probaveris sine dolo malo te desiisse possidere, deinde coeperis possidere et ego a te petam: non nocebit mihi exceptio rei iudicatae <vel in iudicium deductae>.

Si he reivindicado de ti una cosa que me pertenece, pero si tú has sido absuelto por la razón de que has probado que he perdido la posesión sin dolo y si tú has comenzado luego a poseer la cosa y que yo te la reclamo [una vez más], en este caso la exceptio rei indicatae <vel in iudicium deductae $>$ no me será opuesta.

A ha reclamado una cosa que le pertenece de B por una rei vindicatio; este último ha sido absuelto porque ha perdido sin dolo después de la litis contestatio la posesión de la cosa reivindicada, lo que $\mathrm{B}$ ha probado ante el juez. Luego, B ha readquirido la posesión y A intenta nuevamente contra B la reivindicación. Gayo le niega la posibilidad de oponer la exceptio $r$. $i$. vel in $i$. $d$. porque el objeto del segundo proceso de propiedad no es idéntico a la res de la sentencia del primer proceso; se trata en efecto de una nueva posesión del deman- dado. Lo único del primer proceso que es mencionado por el jurista es la absolución del demandado. Es llamativo que la deductio in iudicium de la acción en el primer proceso no tenga ningún rol.

\section{44.2.9.1 Ulpianus 1.75 ad edictum} Si quis fundum, quem putabat se possidere, defenderet, mox emerit: re secundum petitoren iudicata an restituere cogatur? Et ait Neratius, si actori iterum petenti obiciatur exceptio rei indicatae <vel in iudicium deductaes, replicare eum oportere de re secundum se iudicata.

Si alguien (B) que pensaba que poseía un fundo, lo ha defendido [contra la reivindicación intentada por A] y lo ha comprado después, ¿puede aún ser constreñido a restituir la cosa, si la sentencia ha sido pronunciada a favor del demandante [ya que el juez ha decidido que A era el propietario, mientras que $\mathrm{B}$ era absuelto al no poseer]? Neracio dijo que si la exceptio rei iudicatae <vel in indicium deductae> es opuesta a $A$, cuando él reivindica por segunda vez el fundo de B, este último podrá oponer a esta excepción una replicatio según la cual la sentencia [sobre la propiedad] le ha sido favorable.

El caso a propósito del cual Ulpiano nos transmite la opinión de Neracio es el siguiente. A reivindicó un fundo de $\mathrm{B}$, quien pensaba erróneamente que era su posesor; por ejemplo, porque lo confundía con un fundo vecino. El juez expresó en su sentencia que A era el propietario del fundo, pero absolvió a $\mathrm{B}$, porque éste no tenía, según el juez, la posesión del fundo. Poco después, $\mathrm{B}$ compró [del non-dominus $\mathrm{X}$ ] el fundo $\mathrm{y}$, como comprador, comenzó a poseerlo. A no puede ejecutar la sentencia, porque el juez ha absuelto a B. Él incoa entonces un se- 
gundo proceso de propiedad contra B quien puede oponer la exceptio r. $i$. vel in $i$. $d$. a la reivindicación de A. Pero sería iniquissimum, como Juliano escribió en D. 44.2.16, que el efecto de esta excepción sea favorable a quien contra quem iudicatum est. Es por lo tanto comprensible que ya Neracio, algunas décadas antes de Juliano, haya propuesto dar a A, contra la exceptio r. i. vel in i. d., una replicatio según la cual la sentencia sobre eadem res (es decir, la propiedad) había sido en su favor. Aquí, tal como en los otros textos que estudiamos en esta conferencia, no se encuentra ningún rastro de la res in iudicium deducta en el proceso precedente y la mención de una replicatio es más natural por la pluma de Neracio que por aquélla de los compiladores.

\section{44. 2.9 pr. Ulpianus $l .75$ ad edictum}

Si a te hereditatem petam, cum nibil possideres, deinde, ubi coeperis aliquid possidere, hereditatem petam, an noceat exceptio ista? et putem, sive fuit iudicatum hereditatem meam esse, sive adversarius, quia nihil possidebat, absolutus est, non nocere exceptionem.

Si reclamo de ti una sucesión, mientras tú no posees ninguna cosa [hereditaria] y yo reclamo entonces [una vez más] la [misma] sucesión, desde que has comenzado a poseer algo [de la sucesión], la pregunta es si esta excepción [es decir, la exceptio $r$. i. vel in i. d.] puede ser opuesta, sea que el juez ha decidido que la sucesión era mía [pero que el demandado debía ser absuelto a falta de posesión], sea que el demandado fuera absuelto por la [sola] razón de que no poseía ninguna cosa hereditaria.

Una persona, llamada Ego (E) ha intentado la hereditatis petitio contra otra per- sona, llamada $T u(T)$ y ha sido desestimada, porque $T$, quien no puede ser demandado sino si posee pro herede o pro possessore, no estaba en posesión de ninguna res hereditaria. Enseguida $\mathrm{T}$ ha comenzado a poseer algo que era parte de la sucesión; subsecuentemente, $\mathrm{E}$ ha intentado nuevamente la hereditatis petitio contra él. La pregunta es si $\mathrm{T}$ puede oponer a $\mathrm{E}$ la exceptio r. $i$. vel in $i$. d. Ulpiano responde prudentemente (putem) que si el juez ha decidido en el primer proceso que $\mathrm{E}$ era heredero, pero que T debía ser absuelto por falta de posesión de una cosa que pertenecía a la sucesión o si su sentencia se limitó a esta última decisión, la excepción no puede ser opuesta. Es así - creemos - como hay que interpretar la última frase del texto, cuya redacción no es perfecta. La excepción no puede ser opuesta por $\mathrm{T}$ a la segunda hereditatis petitio intentada por $\mathrm{E}$, ya que se trata de alia res a consecuencia de la adquisición por $\mathrm{T}$ de la posesión de una res hereditaria. Lo que es importante aquí para nosotros, es constatar que lo único que el jurista examina para llegar a su respuesta es el contenido de la sentencia del primer proceso; la litis contestatio de este proceso no es tomada en cuenta.

D. 44.2.9.2 Ulpianus $l .75$ ad edictum (a) Iulianus scribit exceptionem rei iudicatae <vel in iudicium deductae> a persona auctoris ad emptorem transire solere, retro autem ab emptore ad auctorem reverti non debere. (b) quare si hereditariam rem vendideris, ego eandem ab emptore petiero et vicero, petenti tibi non opponam exceptionem "at si ea res iudicata non sit inter me et eum, cui vendidisti».

(a) Juliano escribe que la exceptio rei indicatae <vel in iudicium deductae> pasa normalmente de la persona del predecesor (es decir, del vendedor) al 
comprador, pero que no debe volver del comprador a su predecesor. (b) Es por ello que si tu ( $\mathrm{T}$ ) has vendido (a A) una cosa que pertenece a una sucesión y que yo (E) he intentado la reivindicación contra el comprador (A) y yo gané en el proceso, yo no podré oponer a ti una excepción "sino que si una sentencia no ha sido pronunciada entre mí y aquél a quien le vendiste".

La exceptio r. i. vel in i. $d$. pasa del vendedor al comprador pero no vuelve del comprador al vendedor. Es lo que Juliano escribió, según la parte (a) de este texto de Ulpiano. Así, estamos informados de la práctica en estos dos casos mencionados por Juliano, de los cuales el primero ha sido bastante corriente.

Inspirado por el Casus de este texto escrito por Franciscus Accursius (fin del siglo XIII), doy la siguiente explicación a los dos casos previstos por Juliano en la parte (a) del texto. El primer caso pensado por Juliano es el siguiente. Ego ha intentado la reivindicación de un fundo contra Ticio, la que fue desestimada. Luego Ticio vende el fundo a Sempronio y le ha transmitido la posesión sobre él. Cuando a continuación Ego incoe un proceso de propiedad contra el comprador Sempronio, este último podrá oponer la exceptio r. $i$. vel in $i$. d., pues esta excepción que pertenece al vendedor Ticio pasaba al comprador Sempronio. Ello es comprensible, porque el comprador Sempronio ha recibido su derecho de su vendedor Ticio y recibe la cosa en la posición jurídica que ella tenía respecto de Ticio. Paso al segundo caso previsto por Juliano en la parte (a) del texto de Ulpiano. Puede imaginarse este caso de la siguiente manera. Ego ha reivindicado un fundo de aquél (A) que lo ha comprado de $\mathrm{V}$, lo que es desestimado. Luego $\mathrm{V}$ ha recuperado este fundo luego de una in diem addictio o de una lex commissoria. Cuando Ego intenta después una rei vindicatio relativa al fundo contra $\mathrm{V}$, este último no puede oponer la exceptio r. $i$. vel in $i$. $d$. porque esta excepción, que había estado a disposición de A no ha vuelto de A a V. Ello es comprensible, porque $\mathrm{V}$ no recibe ningún derecho de A; para él (V) el proceso que ha tenido lugar entre Ego y A es una res inter alios acta. En estos dos casos no se trata para nada de la preclusión de la acción como consecuencia de la litis contestatio que no tiene, aparentemente, ningún rol.

Examinemos ahora la parte (b) del texto. Ulpiano formula una decisión relativa a un caso difícil basándose sobre la segunda parte de la cita de Juliano en la parte (a) del texto (retro autem ab emptore ad auctorem reverti non debere). Este caso es el siguiente: una persona llamada $T u$ ha vendido al comprador A una cosa que pertenece a una sucesión y le ha transferido la propiedad. Luego, una persona llamada Ego ha reivindicado esta cosa de A. Se puede suponer que estas dos personas, Ego y A sostienen ambos ser el heredero único de la misma sucesión. Ego ha ganado el juicio. A le ha entregado la cosa. Luego, el vendedor Tu intenta la rei vindicatio de la cosa contra Ego. La exceptio no puede ser opuesta por Ego a $T u$, porque la sentencia sobre la propiedad entre Ego y A, a quien Tu, le vendió la cosa no obliga al vendedor de A (a saber, $T u$ ). Para el vendedor $T u$ el proceso que ha tenido lugar entre Ego y A es una res inter alios acta y no puede invocar la res iudicata hecha en su favor. Al final del texto, el jurista incluso inventa la redacción de una excepción imaginaria que le rechaza al demandado del segundo proceso, Ego: "sino que si una sentencia no ha sido pronunciada entre mí y aquél a quien le vendiste”. Un 
tal esbozo de una cláusula de la exceptio $r$. $i$. vel in $i . d$. es sin duda un argumento para la clasicidad de este texto de Ulpiano. No es sorprendente que Ulpiano no diga nada sobre la litis contestatio del proceso que ha tenido lugar entre Ego y A, ya que la acción intentada por Tu contra Ego no es la misma que la que se intenta por Ego contra A. Esta parte del texto de Ulpiano D. 44.2.9.2 no puede por consiguiente tener un rol en nuestra argumentación a favor de la teoría de la absorción de la res in iudicium deducta por la res iudicata.

El último texto que interpretaremos, y que es al mismo tiempo el más complicado, es Ulpiano D. 44.2.11.3.

\section{44.2.11.3 Ulpianus $l .75$ ad edictum (a) Item Iulianus scribit: cum ego et tu heredes Titio existitissemus, si partem fundi quem totum hereditarium dicebas, a Sem- pronio petieris et victus fueris, mox eandem partem a Sempronio emero, agenti tibi mecum familiae erciscundae exceptio (scil. rei indicatae vel in indicium deductae) obstabit, quia res indicata sit inter te et venditorem meum: (b) nam et si ante (scil. a te) eandem partem petissem et agerem fa- miliae erciscundae, obstaret exceptio "quod res iudicata sit inter me et te".}

(a) En seguida, Juliano escribe : si, en el caso en que yo y tú hemos devenido herederos de Ticio, tú has intentado contra Sempronio una vindicatio por parte que concierne a un fundo respecto del cual sostienes que es enteramente hereditario $\mathrm{y}$ has perdido el proceso, y si yo he comprado después esta parte de Sempronio, en este caso, si tú intentas contra mí la actio familiae erciscundae, podré oponer la exception (rei iudicatae vel in iudiicum deductae), porque la cosa ha sido juzgada entre ti y mi vendedor. (b) Pues igualmente, si yo he intentado antes (contra ti) una vindicatio pro parte concerniente al mismo fundo y yo incoo [luego contra ti] la actio familiae erciscundae, la exceptio "que una sentencia haya sido pronunciada en este asunto entre tú y yo" podría ser opuesta.

Comienzo con la estructura o la composición del texto. Juliano, citado por Ulpiano, discute un caso difícil en la parte (a); un caso menos complicado es examinado en la parte (b) del texto. Es posible que Ulpiano haya agregado este caso para hacer más comprensible la decisión de Juliano en la parte (a). Reflexionando más prolongadamente, pienso que la citación de Juliano continúa en la parte (b) y que Juliano mismo ha invocado la decisión en el caso tratado en la parte (b) para hacer más aceptable su decisión tomada en la parte (a). Él, por consiguiente, ha utilizado la decisión ya aceptada en el caso más fácil de la parte (b) como argumento en el caso complicado de la parte (a).

El caso de la parte (a) es el siguiente. Ego y Tu han devenido los herederos de Ticio. $T u$ ha intentado la vindicatio pro parte (por la mitad) concerniente a un fundo contra Sempronio, sosteniendo que el fundo entero formaba parte de la sucesión, y perdió el proceso. Según el juez, el fundo en cuestión no era una res hereditaria. Luego, Ego ha comprado esta parte en copropiedad del fundo de Sempronio. Enseguida, Tu ha intentado la actio familiae erciscundae contra Ego sosteniendo, por segunda vez, que el fundo era una res hereditaria y pidió su división. Según Juliano, se trata de eadem res. Ego puede entonces oponer a esta acción la exceptio r. $i$. vel in i. d., pues sobre esta cosa una sentencia ha sido pronunciada entre Tu y Sempronio, aquél que había vendido la pars pro indiviso del fundo a Ego. Era en el derecho una 
práctica estable, tal como lo sabemos por la cita de una afirmación de Juliano citada en el texto ya estudiado (Ulpiano D. 44.2.9.2), que la exceptio r. $i$. vel in i. d. pasara al comprador (Ego en nuestro texto) tal como había podido ser opuesta por el vendedor (Sempronio en nuestro texto).

En la parte (b) el rol de las personas ha cambiado. Accursius escribe justamente en la glosa "si a te" (la Vulgata a si a te en lugar de si ante de la Florentina): mutat personas. En el caso de la parte (a) del texto, el que primero ha intentado la vindicatio pro parte es $T u$, mientras que en la parte (b) el primero que intenta esta reivindicación es Ego. Juliano introduce en la parte (b) un caso más simple para servir de argumentación a su decisión sobre el caso difícil de la parte (a). Él ha eliminado la complicación que había tenido lugar en el primer proceso entre uno de los herederos y quien devino posteriormente el vendedor del otro. En la parte (b) Ego intentó la vindicatio pro parte que concernía el fundo contra su coheredero $T u$, habiendo sido desestimado. Luego, Ego intenta contra Tu la actio familiae erciscundae y pide la división del fundo. Se trata de una acción relativa a eadem res sobre la cual una sentencia judicial ha sido pronunciada y por ello la exceptio $r$. $i$. vel in $i$. $d$. puede ser opuesta. El texto original ha, verosímilmente, dado al final del texto el título y la redacción de la exceptio $r$. $i$. vel in $i$. $d$. en su conjunto. En la versión del Digesto, los compiladores han eliminado las palabras que conciernen a la res in iudicium deducta, habiendo sin embargo conservado las palabras de la cláusula sobre la res iudicata: "quod res iudicata sit inter me et te". Constatamos el mismo fenómeno en los dos casos examinados por Juliano en este texto de Ulpiano. Había en el proceso anterior una litis contestatio y una sentencia; no se halla ninguna palabra sobre la res in iudicium deducta y toda la atención del jurista se encuentra concentrada sobre la res iudicata. Se halla también allí la cita de las palabras de la cláusula sobre la res iudicata de nuestra excepción. Todo aquello da testimonio de un origen clásico innegable.

Nuestra conclusión puede ser breve: los cinco textos de Gayo y de Ulpiano que nos permiten conocer igualmente las opiniones de Neracio y (sobre todo) de Juliano, prueban que en la exceptio r. $i$. vel in i. d. los efectos preclusivos de la cosa deducida en justicia eran absorbidos por aquellos provocados por la sentencia del juez. La mención de una replicatio en D. 44.2.9.1, de una cláusula imaginaria de nuestra excepción que era rechazada en D. 44.2.9.2, y la formulación de la cláusula sobre la res iudicata en D. 44.2.11.3 son argumentos para admitir que los razonamientos cimentados sobre la sententia iudicis son clásicos.

Así, hemos terminado nuestro estudio común relativo a dos problemas concernientes a la exceptio r. i. vel in i. $d$. Esta excepción era una institución procesal cuya unidad en dos sentidos no puede ser cuestionada, y la preclusión provocada por la litis contestatio era absorbida por aquella que se desprendía de la res iudicata. 
